\title{
A Mathematical Model on Interaction of Smoke Layer with Sprinkler Spray
}

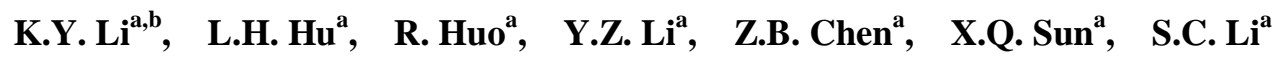 \\ a State Key Laboratory of Fire Science, \\ University of Science and Technology of China, \\ Hefei 230027, China \\ ${ }^{\mathrm{b}}$ College of Environmental Science and Engineering, \\ Southwest Jiaotong University, \\ Chengdu 610031, China
}

Corresponding author: Tel: (86) 551 3606446; Fax: (86) 551 3601669; Email address: hlh@ustc.edu.cn, huoran@ustc.edu.cn, steveli@mail.ustc.edu.cn Postal address: State Key Laboratory of Fire Science, University of Science and Technology of China, Hefei, Anhui, 230026, China

Submitted September, 2007 Revised February, 2008 


\begin{abstract}
A mathematical model was developed for predicting the downward descending behavior of the buoyant smoke layer under sprinkler spray. The behavior of the smoke layer was determined by considering the interaction between the drag force of the sprinkler spray and the buoyancy force of the hot smoke layer itself in the spray region. The smoke layer may be pulled down with its thickness increased at the center of the spray region due to the cooling and drag effects of the sprinkler spray, thus to form a downward "smoke logging” plume. In the mathematical model developed in this paper, the critical condition under which the smoke layer lost its stability, as a serious concern, was predicted. Additionally, the length of the downward plume, which was rarely investigated before, was also further calculated. Full scale experiments were carried out to validate the model. Results showed that the predictions, including the critical condition and the length of the plume, by the mathematical model agreed well with that observed and measured in the experiments. The length of the downward plume was shown to increase with the sprinkler operating pressure by an approximately linear correlation.
\end{abstract}

\title{
KEYWORDS
}

Smoke layer; sprinkler spray; interaction; smoke logging plume length; drag force; buoyancy force 


\section{INTRODUCTION}

Automatic sprinkler systems are required to be installed in many building such as hotels, factories and shopping malls. The sprinkler spray systems, which can directly control or suppress the fire, are very reliable in protecting buildings against fire [1-5]. But on the other hand, the buoyancy of the hot smoke layer, which supports the stratification, decreases due to the cooling effect by the water spray. The drag force produced by the water droplets also pulls the stratified smoke layer downward. These two factors both can lead to the loss of stability of the smoke layer stratification. Under such a condition, the smoke layer will fall down to a lower level, until it reaches the floor, resulting in "smoke logging". The smoke logging is a risk to evacuation and fire fighting [1-10]. However, this behavior was not considered in the most popular zone fire models, such as the latest version of CFAST (6.0). A physical model should be developed to address this behavior.

The interaction of smoke layer with sprinkler spray was studied by Bullen [2] in 1974. A smoke layer assumed with a constant thickness was considered. The sprinkler spray was taken as water droplets with constant diameter calculated from the sprinkler pressure. A physical parameter known as the drag-to-buoyancy ratio was calculated for the entire smoke layer to assess its stability. Morgan and Baines [1, 6] further included the convective heat transfer from the smoke layer to the sprinkler spray in the model, which was ignored by Bullen. Numerical modeling was conducted later by Alpert [7], Chow [8-10], Hoffmann [11] and Gardiner [12]. Interaction of sprinkler spray with ventilation was also studied by Heselden [13], Hinkley [14] and McGrattan [15]. More recent work had also been reported by Heskestad [16] and Cooper $[17,18]$. The behavior of the smoke layer under a sprinkler spray was studied by Cooper in 1995 with a physical model developed. In Cooper's model, it was considered that the 
smoke layer element of unit volume below the sprinkler nozzle was pulled down by the drag force of sprinkler droplets and pushed up by its own buoyancy. The shape of the spray region was assumed to be a cone with the apex at the sprinkler nozzle. The temperature of the smoke layer element was determined by the heat transfer process between the smoke layer and the spray droplets.

As reported by Cooper $[17,18]$, the smoke was downward-buoyant in the upper layer of the spray region because its temperature was less than that of the smoke outside the region. So the smoke layer element below the sprinkler nozzle should move downward to penetrate the interface, descend into the lower cool air layer and form a downward "smoke-logging" plume under the sprinkler spray. However, in some experiments reported [2-5], the smoke layer would still remain stable and no downward "smoke-logging" plume was seen under certain spray conditions. On the other hand, the smoke layer thickness was not even considered in Cooper's model, but it will certainly have a major contribution. Although there were numerous studies on the interaction of smoke layers with sprinkler sprays, they were mostly focused on the critical condition under which the smoke layer will lose its stability. It should be also noted that the hot smoke will become upwardly-buoyant after penetrating the smoke layer interface as the density of the lower ambient air greater than the smoke being pulled down $[17,18]$. So, the downward smoke flow pulled down by the sprinkler spray decelerates below the smoke layer interface and may stop before reaching floor level. The question arising then is: what will the length of the "smoke logging" plume finally be, or how far will the smoke layer be pulled down by the sprinkler spray? However, this has rarely been investigated.

A mathematical model is developed in this paper to describe the "smoke-logging" behavior of a smoke layer under a sprinkler spray. The critical condition under which 
the stable smoke layer stratification will be lost is determined. The length of the “smoke-logging” plume, under the condition that the smoke layer loses its stability, is predicted with smoke layer thickness and temperature, and sprinkler operating pressure considered. Finally, full scale experiments were carried out to validate the mathematical model.

\section{MATHMATICAL MODEL}

\section{Assumptions}

1. The viscous force derived from the deformation of the smoke layer is ignored as it is too small relative to the drag force of the droplets and the buoyancy force of the smoke layer.

2. The water density distribution (WDD) in the horizontal cross section of the sprinkler spray is uniform.

3. Small oscillations of smoke layer interface are not considered, although they are observed in the experiments.

4. The behavior of the smoke layer under a sprinkler spray was considered by taking a column element of the smoke layer (unit base area $\delta \Delta$ and fixed height, $h-x_{1}$, (that was covered by the spray)) into account, as shown in Figure1. The smoke layer behavior is described as this column element being pulled down by the drag force of the sprinkler spray droplets and at the same time pushed back up by its own buoyancy, based on the fact that the similar phenomenon was observed during the experiments.

5. The downward vertical velocity of the smoke layer was neglected when considering the drag force due to the relative vertical velocity between the droplets and the smoke layer, since vertical velocity of the smoke layer is very small in relation to the velocity of the droplets. 
6. It was mentioned by Cooper [17] that recirculation flows would be caused by the downward "smoke logging” plume and lead to some increase of the thickness of the stable smoke layer. The complex recirculation flows induced by droplet drag is not taken into account in the current analysis.

\section{Drag force of the sprinkler spray droplets}

As shown in Figure 1, the darkened region of the smoke layer is that affected by the spray. The initial thickness of the smoke layer is $h$. Initial velocity of the smoke layer is assumed to be zero. The vertical drag force caused by a spray droplet is then expressed as [2, 3]:

$$
\begin{gathered}
D(x)=k_{d} v^{2} \\
k_{d}=\frac{\rho_{g}(x) C_{D} A_{d}}{2}
\end{gathered}
$$

where $D(x)$ is the vertical drag force of a single water droplet at coordinate $x(N)$, $v$ is the vertical velocity of the droplet $(\mathrm{m} / \mathrm{s}), \rho_{g}(x)$ is the density of the smoke $\left(\mathrm{kg} / \mathrm{m}^{3}\right), C_{D}$ is the drag coefficient and is taken to be 0.6 when $\operatorname{Re}$ is $10^{1} \sim 10^{2}$ [1-6] and $A_{d}$ is the central cross section area of the droplet $\left(m^{2}\right)$. The momentum equation of the droplet is:

$$
m_{d} g-k_{d} v^{2}=m_{d} \frac{d v}{d t}=m_{d} v \frac{d v}{d x}
$$

where $m_{d}$ is the mass of the droplet $(\mathrm{kg}), g$ is the acceleration of gravity $\left(\mathrm{m} / \mathrm{s}^{2}\right)$. Integrating the equation (3), the vertical velocity $v$ can be expressed as:

$$
v^{2}=\frac{m_{d} g}{k_{d}}+C_{1} \exp \left(-\frac{2 k_{d} x}{m_{d}}\right)
$$

The constant $C_{1}$ is determined by the vertical velocity boundary of the droplet. 
According to the experimental results by Sheppard [19], the velocity of a droplet $0.2 \mathrm{~m}$ below the sprinkler is approximately $0.4 \sim 0.6$ times $\sqrt{\frac{2 p_{d}}{10^{-6} \rho_{d}}}$. An average value of 0.5 is taken here. As the velocity direction of the spray droplets when leaving the sprinkler is vertically downward, the constant $C_{1}$ for the droplets is deduced to be:

$$
C_{1}=\left(0.25\left(\sqrt{\frac{2 p_{d}}{10^{-6} \rho_{d}}}\right)^{2}-\frac{m_{d} g}{k_{d}}\right) / \exp \left(-\frac{2 k_{d} x_{0}}{m_{d}}\right)
$$

where $p_{d}$ is the operating pressure of the sprinkler ( $\left.M P a\right), \rho_{d}$ is density of the water $\left(\mathrm{kg} / \mathrm{m}^{3}\right)$ and $x_{0}=0.2 \mathrm{~m}$.

The envelope curve of the spray region is approximately paraboloid according to the NFPA13HB [20] and the external shape curve is defined as:

$$
y^{2}=E x
$$

thus the horizontal cross section area of the spray region at coordinate $x$ is:

$$
S(x)=\pi E x
$$

where $S(x)$ is the area of the cross section $\left(m^{2}\right)$. The manual of the sprinkler and experimental observations indicate that the wetted area at $3 \mathrm{~m}$ below the ceiling is a circle with radius of approximately $3 \mathrm{~m}$ [2, 19-21]. Then the coefficient $E$ is deduced to be 3 . The water density distribution can be assumed to be uniform in the cross section area $[2,21]$. The droplet number, $n(x)$, in the sub-volume of the smoke layer column element of height $d x$ at coordinate position $x$ is then expressed as:

$$
n(x)=\frac{\dot{M}}{m_{d} S(x) \nu} d x
$$

where $\dot{M}$ is the discharge mass flow rate out of the sprinkler nozzle $(\mathrm{kg} / \mathrm{s})$ : 


$$
\dot{M}=\frac{\rho_{d} K^{\prime} \sqrt{10 p_{d}}}{60 \times 10^{3}}
$$

where $K^{\prime}$ is the flow rate coefficient of the sprinkler $(L /(\min \cdot \sqrt{\text { bar }})$ and taken to be 80 for the sprinkler with nozzle diameter of $12.7 \mathrm{~mm}[19,20])$. The drag force of the droplets on the smoke layer column element at coordinate $x$ is then deduced to be:

$$
D^{\prime}(x)=n(x) D(x)=\frac{\dot{M}}{S(x)} \times \frac{k_{d}}{m_{d}} \sqrt{\frac{m_{d} g}{k_{d}}+C_{1} \exp \left(-\frac{2 k_{d} x}{m_{d}}\right)} d x
$$

where:

$$
k_{d} / m_{d}=\left[\frac{1}{8} \rho_{g}(x) C_{D} \pi d_{d}^{2} / \frac{1}{6} \rho_{d} \pi d_{d}^{3}\right]=\frac{3 \rho_{g}(x) C_{D}}{4 \rho_{d} d_{d}}
$$

with $d_{d}$ is the diameter of the droplet $(m)$. The diameters of different droplets are assumed to be same with a mean diameter $d_{m}$ here, which was calculated by equations (12) - (14) [2, 3, 19, 21]:

$$
\begin{gathered}
d_{m}=C_{m} d_{n} W e^{-\left(\frac{1}{3}\right)} \\
W e=\frac{\rho_{d} U^{2} d_{n}}{\sigma_{w}} \\
U=\frac{\dot{M}}{\rho_{d} \pi d_{n}{ }^{2} / 4}
\end{gathered}
$$

where $U$ is the initial velocity of the water when discharging out of the sprinkler nozzle $(\mathrm{m} / \mathrm{s}), \sigma_{w}$ is the surface tension of water which is taken to be $72.8 \times 10^{-3} \mathrm{~N} / \mathrm{m}$, We is the Weber number and $d_{n}$ is the diameter of the sprinkler nozzle $(m)$. The coefficient $C_{m}$ is taken to be 2.33 for sprinkler with nozzle diameter of $12.7 \mathrm{~mm} \quad[22,23]$.

As shown in Figure 1, the total drag force of the sprinkler spray droplets on the 
smoke layer column element with unit area $\delta \Delta$ is:

$$
D_{x 1}=\int_{x 1}^{h} D^{\prime}(x)=\int_{x 1}^{h}\left[\frac{\dot{M}}{S(x)} \times \frac{k_{d}}{m_{d}} \sqrt{\frac{m_{d} g}{k_{d}}+C_{1} \exp \left(-\frac{2 k_{d} x}{m_{d}}\right)}\right] d x
$$

where $h$ is the thickness of the smoke layer $(m)$. Substituting equation (7) and equation (11) into equation (15) gives:

$$
D_{x 1}=\int_{x 1}^{h}\left[\frac{\dot{M}}{\pi E x} \times \frac{3 \rho_{g}(x) C_{D}}{4 \rho_{d} d_{d}} \sqrt{\frac{4 \rho_{d} d_{d} g}{3 \rho_{g}(x) C_{D}}+C_{1} \exp \left(-\frac{6 \rho_{g}(x) C_{D} x}{4 \rho_{d} d_{d}}\right)}\right] d x
$$

\section{Buoyancy force of the smoke layer column element}

The buoyancy force, $B^{\prime}(x)$, of the sub-volume of the smoke layer column element with a small height of $d x$ at coordinate position $x$ varies with its temperature and is taken as:

$$
B^{\prime}(x)=\left[\rho_{0}-\rho_{g}(x)\right] g=\frac{T(x)-T_{0}}{T(x)} \rho_{0} g d x
$$

where $\rho_{0}$ is air density at ambient temperature $\left(\mathrm{kg} / \mathrm{m}^{3}\right), T(x)$ and $T_{0}$ is the smoke temperature $(K)$ and the ambient temperature $(K)$ respectively. The total buoyancy force on the smoke layer column element with unit area $\delta \Delta$ is then calculated to be:

$$
B_{x 1}=\int_{x 1}^{h} B^{\prime}(x)=\int_{x 1}^{h} \frac{T(x)-T_{0}}{T(x)} \rho_{0} g d x
$$

$T(x)-T_{0}$ in equation (18) can be substituted by the average temperature rise of the smoke layer, assuming that the temperature decays linearly with height in the smoke layer [24, 25]. The equation (18) can be simplified as:

$$
B_{x 1}=\int_{x 1}^{h} \frac{T(x)-T_{0}}{T(x)} \rho_{0} g d x=\frac{\overline{\Delta T}}{\overline{\Delta T}+T_{0}} \rho_{0} g(h-x 1)
$$


where $\overline{\Delta T}$ is the average temperature rise of the smoke layer $(K)$.

\section{Smoke logging behavior}

The droplets directly below the sprinkler in the spray region have the maximum vertically downward velocity while leaving the sprinkler nozzle, as reported by Sheppard [19]. So, the drag force on the smoke layer column element should also be maximal at this position, with coordinates $x=0$ and $y=0$, in the spray region (Figure 2(a)). The smoke layer should first lose its stability here. So, the smoke layer column element with coordinate $y=0$ was only considered here for the smoke layer behavior. This initial drag force to this column element is:

$$
D_{0}=\int_{0}^{h}\left[\frac{\dot{M}}{\pi E x} \times \frac{3 \rho_{g}(x) C_{D}}{4 \rho_{d} d_{d}} \sqrt{\frac{4 \rho_{d} d_{d} g}{3 \rho_{g}(x) C_{D}}+C_{1} \exp \left(-\frac{6 \rho_{g}(x) C_{D} X}{4 \rho_{d} d_{d}}\right)}\right] d x
$$

with $C_{1}$ being a constant which can be determined by equation (5). The initial buoyancy force directly below the sprinkler is:

$$
B_{0}=\frac{\overline{\Delta T}}{\overline{\Delta T}+T_{0}} \rho_{0} g h
$$

The smoke layer column element directly below the sprinkler would move downwards if $D_{0}>B_{0}$, which represents the instability of the smoke layer. As shown in Figure 2(b), when the element moves downward by a distance $S$, the drag force on the column element changes to be:

$$
D_{S}=\int_{S}^{S+h}\left[\frac{\dot{M}}{\pi \mathrm{E} x} \times \frac{3 \rho_{g}(x) C_{D}}{4 \rho_{d} d_{d}} \sqrt{\frac{4 \rho_{d} d_{d} g}{3 \rho_{g}(x) C_{D}}+C_{1} \exp \left(-\frac{6 \rho_{g}(x) C_{D} x}{4 \rho_{d} d_{d}}\right)}\right] d x
$$

The kinetic energy equation of the column element is then taken as: 


$$
J=\int_{0}^{S} D_{S} d S-B_{0} S
$$

where $J$ is the kinetic energy of the column element which is determined by the strength of the drag force $\int_{0}^{s} D_{S} d S$ and the strength of the buoyancy force $B_{0} S$. Substituting equation (22) into equation (23) gives:

$$
\frac{1}{2} \rho_{0} g h V^{2}=\int_{0}^{S}\left(\int_{S}^{S+h}\left[\frac{3 \dot{M} \rho_{g}(x) C_{D}}{4 \pi E \rho_{d} d_{d} x} \sqrt{\frac{4 \rho_{d} d_{d} g}{3 \rho_{g}(x) C_{D}}+C_{1} \exp \left(-\frac{6 \rho_{g}(x) C_{D} x}{4 \rho_{d} d_{d}}\right)}\right] d x-B_{0}\right) d S
$$

where $V$ is the velocity of the smoke layer column element $(\mathrm{m} / \mathrm{s})$. The value of $D_{S}$ decreases as the smoke layer column element moves downwards. The element begins to decelerate when $B_{0}>D_{S}$ and its velocity finally decreases to zero at a certain coordinate position $x$. The maximum distance that the element can move down can be deduced from equation (24) by taking $V$ to be zero:

$$
S=\int_{0}^{S} \int_{S}^{S+h}\left[\frac{3 \dot{M} \rho_{g}(x) C_{D}}{4 \pi E \rho_{d} d_{d} x} \sqrt{\frac{4 \rho_{d} d_{d} g}{3 \rho_{g}(x) C_{D}}+C_{1} \exp \left(-\frac{6 \rho_{g}(x) C_{D} x}{4 \rho_{d} d_{d}}\right)}\right] d x d S / B_{0}
$$

The 3rd-order Simpson numerical method is applied for calculating $D_{S}$ and $S$ in equation (22) and equation (25). The length of the downward "smoke logging” plume $L$ should be:

$$
L=S+h
$$

\section{EXPERIMENTS}

The experimental apparatus is shown in Figure 3. It consisted of two parts: the burning cabin and the sprinkler cabin. As shown in Figure 3, pool fires were burned in the burning cabin to generate an initial stable smoke layer in the upper region of the sprinkler region. The burning cabin was $4 \mathrm{~m}$ long, $2 \mathrm{~m}$ wide and $2.5 \mathrm{~m}$ high. Six air 
supply openings with length of $0.8 \mathrm{~m}$ and height of $0.4 \mathrm{~m}$ were located on both sides of the cabin. The sprinkler cabin was $4.2 \mathrm{~m}$ long, $4.2 \mathrm{~m}$ wide and $4.2 \mathrm{~m}$ high. A smoke curtain $2.0 \mathrm{~m}$ high was installed below the top of the cabin to maintain an initial stable smoke layer with thickness of $2.0 \mathrm{~m}$. A measurement gauge $4.2 \mathrm{~m}$ high with a resolution of $\pm 0.01 \mathrm{~m}$ was placed in front of the cabin for measuring the length of the downward "smoke logging" plume as shown in Figure 3(b). The uncertainty of the observed length of the "smoke logging" plume was estimated to be less than +0.05 m. 4 thermocouple trees were distributed in a circle of diameter $1.2 \mathrm{~m}$ with the sprinkler at the centre. The vertical interval of the thermocouples is $0.3 \mathrm{~m}$. Bare bead K type thermocouples were used with uncertainties estimated to be of less than $\pm 2^{\circ} \mathrm{C}$. The thermocouples were protected by saddle steel waterproofing caps which are used for avoiding the influence of the water droplets on the temperature measurement of the thermocouple bead.

As shown in Figure 3(c), ZSTP-15 Sprinkler with nozzle diameter of $12.7 \mathrm{~mm}$ was used for the tests. The sprinkler is made by Copper Alloys with the flow rate coefficient of 80 . The sprinkler was installed in the central of the sprinkler cabin roof as a standard pendant. A pressure reduction valve and pressure transducer and transmitter were installed on the pipe to control the sprinkler operating pressure with an accuracy of $\pm 0.002 \mathrm{MPa}$. A digital video camera was used to record the tests process so as to determine the length of the downward "smoke logging" plume.

In total, 19 tests were conducted with 3 different fire heat release rates. Diesel oil was used as the fuel for of the pool fires. The heat release rate of the pool fires was determined by the mass loss rate measured by an electronic balance with accuracy of $\pm 1 \mathrm{~g}$. The heat of combustion of the diesel oil was taken to be $42000 \mathrm{~kJ} / \mathrm{kg}$. The combustion efficiency was taken to be 0.8 according to previous measurements in 
the ISO 9705 Room Calorimeter [26]. The sprinkler spray was discharged at $50 \mathrm{~s}$ after ignition when the upper part of the sprinkler cabin was filled with a stable smoke layer. The total burning time of each test was about 400 s. The operating pressure of the sprinkler was varied from 0.03 to $0.13 \mathrm{MPa}$.

\section{RESULTS AND DISCUSSION}

\section{The stability of the smoke layer under sprinkler spray}

The smoke layer would remain stable when the operating pressure was relatively low. Under this condition, the two zone structure of the smoke layer was not broken as the smoke layer temperature was relatively high. The interface between the smoke and the air was clear in the sprinkler cabin. The thickness of the smoke layer increased a bit due to the dilution effects of the water droplet to the layer. It was less than $2.3 \mathrm{~m}$ in all of the tests under this condition. The experimentally measured data are summarized in Table 1, with $D_{0}, B_{0}$ and the "smoke logging" plume length calculated. Figure 4 presents typical photos of the smoke layer in test A1 and C2. As shown in the Figure, there was no downward smoke plume which would have indicated the instability of the smoke layer. In these two tests, as well as in test B1 and C1, the smoke layer remained stable at the top of the sprinkler cabin. This was in accordance with the mathematical model as $D_{0}$ were calculated to be less than $B_{0}$ in these tests as shown in table 1.

The smoke layer was shown to lose its stability when $D_{0}>B_{0}$. Under this condition, the operating pressure was relatively high and the smoke layer temperature was relatively low, the stable two zone structure of the smoke-air layer was broken and a downward "smoke logging" plume was shown. The plume penetrated the interface and brought the smoke to the lower part of the cabin. 
Figures 5(a) - (f) present typical photos of tests C3-C8 (sprinkler operating pressure varying from $0.07 \mathrm{MPa}$ to $0.13 \mathrm{MPa}$ ). As shown in these Figures, the smoke layer became unstable. Part of the smoke layer in the spray region moved downwards and formed the "smoke logging" plume. The higher the sprinkler operating pressure, the greater the length of the downward plume was. According to equations (15) - (16) and equations (20) - (26), the drag force of the sprinkler spray decreases with the radial distance away from the centerline of the spray region. Thus the shape of the downward "smoke logging" plume should be like an inversed "bowl". This is clearly seen during the experiments, as shown Figure 5. The volume of the downward smoke plume also enlarged horizontally as the operating pressure increased. In Table 1, $D_{0}>B_{0}$ is found for tests C3- C8. It can be seen from above that the relative magnitude of $D_{0}$ and $B_{0}$ calculated can be regarded as a criterion for stability of the smoke layer under sprinkler spray. The smoke layer remains stable when $D_{0}<B_{0}$ and becomes unstable when $D_{0}>B_{0}$.

As shown in Table 1, for fire types of A and B with relatively low heat release rate, the average smoke layer temperatures were also relatively low. The downward "smoke logging” plume finally reached the floor when the sprinkler operating pressure was increased from $0.07 \mathrm{MPa}$ to $0.09 \mathrm{MPa}$, respectively, while for type $\mathrm{C}$ fire with a relatively high heat release rate, it was $0.13 \mathrm{MPa}$. It was clearly shown that higher sprinkler operating pressure was needed for pulling down the smoke to the floor level for smoke layer with higher temperature.

\section{Length of the downward plume}

The length of the downward "smoke logging” plume calculated by equations (20) - (26) was compared with that experimentally measured value in Figure 6. According 
to the mathematical model, with the increase of the operating pressure and thus the discharge mass flow rate $\dot{M}$, the drag force $D_{S}$ of the sprinkler spray increased, which will lead to the increase of the moving distance and thus the length of the downward plume. This trend was in accordance with what was measured in the experiments. The plume lengths predicted quantitatively by the mathematical model agreed fairly well with the experimental data. However, the calculated values were a bit lower than the experimental values due to the fact that the water density distribution is not uniform in the horizontal cross section of the spray region, which was not taken into account in the mathematical model. The real distribution is that the water density in the center of cross section is a bit larger than that in the outer region [21]. Thus the current mathematical model should slightly underestimate the length of the downward plume.

The downward moving distance $S$ was correlated with the operating pressure in Figure 7(a) for tests C3 - C8. It was shown that the variation of $S$ with the operating pressure fitted the following linear regression formula with correlation coefficient of 0.99:

$$
S=27.23 p_{d}-1.63
$$

This indicates that the downward moving distance $S$ (or the length of the downward plume $L$ ) increases linearly with the operating pressure $p_{d}$. Figure 7(b) presents the variation of the average temperature rise of the smoke layer in the sprinkler cabin with the operating pressure. It was shown that the temperature rise reduced while the operating pressure increased. However, with the increase of the sprinkler operating pressure, the reduction to the smoke layer temperature seemed to be less effective. So, it can be drawn from above that a optimal operating pressure should be selected for the sprinkler, to achieve maximum cooling of the smoke layer while at the same time 
ensuring that the sprinkler spray does not break the stability of the smoke layer greatly and pull down the smoke layer to the floor lever to threaten the safety of the people. For example, the optimal operating pressure, as can be seen from Figure 7, should be about $0.07 \mathrm{MPa}$ for the case of the type $\mathrm{C}$ fire in this study.

\section{CONCLUSIONS}

A new mathematical model was developed in this paper to examine the interaction of smoke layer with sprinkler spray. The drag force of the sprinkler spray droplets and the buoyancy force of the smoke layer were numerically calculated. The critical condition under which the stability of the smoke layer stratification lost and in addition the length of the downward "smoke logging" plume was predicted. Full scale experiments were carried out to validate the mathematical model. The predictions of the mathematical model were shown to agree well with the experimental data and observations. The smoke layer remains stable when $D_{0}<B_{0}$ and becomes unstable when $D_{0}>B_{0}$. With the increase of the sprinkler operating pressure, the length of the downward "smoke logging” plume increased monotonously linearly, but the cool effect to the smoke layer was shown to be less effective. The lengths of the downward “smoke logging” plume predicted by the mathematical model agreed fairly well with

the experimental data, although were a bit lower due to the fact that water density distribution is not uniform in the horizontal cross section of the spray region but was ignored in the mathematical model. This factor will be included to improve the current model in the future work. The implementing the current mathematical model into a zone fire model is also ongoing and will be reported later. 


\section{ACKNOWLEDGEMENT}

This work was supported by the Natural Science Foundation of China (NSFC) under Grant No. 50536030 and Anhui Provincial Natural Science Foundation of China under Grant No. 070415224. 


\section{NOMENCLATURE}

$A_{d}: \quad$ central cross section area of the droplet, $\mathrm{m}^{2}$;

$B_{0}$ : buoyancy force on the smoke layer column element below the sprinkler, $N$;

$B^{\prime}(x)$ : buoyancy force of unit volume at coordinate $x, N$;

$B_{x 1}$ : total buoyancy force on the smoke layer column element with unit area, $N$;

$C_{D}:$ drag coefficient;

$C_{m}$ : coefficient for calculating the mean diameter;

$d_{d}$ : diameter of the droplet, $m$;

$d_{m}:$ mean diameter of all droplets, $m$;

$d_{n}$ : diameter of the sprinkler nozzle, $m$;

$D(x)$ : vertical drag force of a single water droplet at coordinate $x, N$;

$D_{0}$ : initial drag force on the smoke layer column element below the sprinkler, $N$;

$D_{S}$ : drag force on the smoke layer column element directly below the sprinkler when moved downward with a distance of $S, N$;

$D^{\prime}(x)$ : drag force of unit volume at coordinate $x, N$;

$D_{x 1}$ : total drag force on the smoke layer column element with unit area, $N$;

$E$ : coefficient of curve equation for the external shape of the spray region;

$g$ : acceleration due to gravity, $\mathrm{ms}^{-2}$;

$h$ : $\quad$ initial thickness of the smoke layer, $m$;

$J$ : $\quad$ kinetic energy of the column element, $J$;

$k_{d}$ : coefficient for calculating $D(x), \mathrm{ms}^{-1}$;

$K^{\prime}$ : flow coefficient of the sprinkler $L /(\min \cdot \sqrt{b a r})$;

$L$ : length of the "smoke logging" plume, $m$; 
$m_{d}$ : mass of the droplet, $\mathrm{kg}$;

$\dot{M}$ : discharge mass flow rate of the sprinkler nozzle, $\mathrm{kgs}^{-1}$;

$n(x)$ : water droplet numbers in unit volume at coordinate $x$;

$p_{d}$ : operating pressure of the sprinkler, $\mathrm{MPa}$;

$S$ : moving distance of the smoke layer column element directly below the sprinkler, $m$;

$S(x)$ : area of the horizontal cross section of the spray region at coordinate $x, m^{2}$;

$T(x)$ : smoke temperature, $K$;

$\overline{\Delta T}$ : average temperature rise of the smoke layer, $K$;

$T_{0}: \quad$ ambient temperature, $K$;

$U$ : initial velocity of the water when discharging out of the sprinkler nozzle, $\mathrm{ms}^{-1}$;

$v$ : $\quad$ vertical velocity of the droplet, ; $\mathrm{ms}^{-1}$

$V:$ velocity of the smoke layer column element, $\mathrm{ms}^{-1}$;

We : Weber number;

$x_{1}$ : coordinate $x$ of the apex of the smoke layer column element, $m$;

\section{Greek symbols}

$\rho_{d}$ : density of the water, $\mathrm{kgm}^{-3}$;

$\rho_{g}:$ density of the smoke, $\mathrm{kgm}^{-3}$;

$\rho_{0}$ : density of the air at ambient temperature, $\mathrm{kgm}^{-3}$;

$\sigma_{w}:$ surface tension of water, $\mathrm{Nm}^{-1}$; 


\section{REFERENCES}

[1] Morgan H P. Heat Transfer from a Buoyant Smoke Layer Beneath a Ceiling to a Sprinkler Spray 1-A Tentative Theory. Fire and Materials, 1979; 3: 27-33.

[2] Bullen M L. The Effect of a Sprinkler on the Stability of a Smoke Layer Beneath a Ceiling. In: Fire Research Note 1016, Fire Research Station, Borehamwood, UK, 1974; 1-11.

[3] Chow W K, Yao B. Numerical Modeling for Interaction of a Water Spray with Smoke Layer. Numerical Heat Transfer, 2001; 39: 267-283.

[4] Chow W K, Tong.A C. Experimental Studies on Sprinkler Spray-Smoke Layer Interaction. Journal of Applied Fire Science, 1995; 4: 171-184.

[5] Zhang C F, Huo R, Li Y Z. Stability of Smoke Layer under Sprinkler Water Spray. ASME’s 2005 Summer Heat Transfer Conference, San Francisco, CA, 2005.

[6] Morgan H P, Baines K. Heat Transfer from a Buoyant Smoke Layer Beneath a Ceiling to a Sprinkler Spray 2-An Experiment. Fire and Materials, 1979; 3: 34-38.

[7] Alpert R L. Numerical modeling of the interaction between automatic sprinkler sprays. Fire Safety Journal, 1985; 9: 157-163.

[8] Chow W K, Fong N K. Numerical Simulation on Cooling of the Fire-induced Air Flow by Sprinkler Water Spray. Fire safety Journal, 1991; 17: 263-290.

[9] Chow W K, Fong N K. Numerical Studies on the Interaction of Sprinklers and the Hot Layer. Architectural Science review, 1993; 36: 103-111.

[10] Chow W K, Cheung Y L. Simulation of Sprinkler-hot Layer Interaction Using a Field Model. Fire and Material, 1994; 18: 359-379.

[11] Hoffmann N F, Galea E R, Markatos N C. Mathematical Modeling of the Fire Sprinkler Systems. Applied Mathematical Modeling, 1989; 13: 298-306.

[12] Gardiner A J. The Mathematical Modeling of the Interaction Between Sprinkler Sprays and the Thermally Buoyant Layers of the Gas from Fires. PhD dissertation, South Bank Polytechnic, London, United Kingdom, 1989.

[13] Heselden A J M. The Interaction of Sprinkler and Roof Venting in Industtial Buildings: the Current Knowledge. Building Research Establishment, Borehamwood, UK, 1984.

[14] Hinkley P L. The Effect of Vents on the Opening of the First Sprinklers. Fire Safety Journal. 
1986; 11: 211-225.

[15] McGrattan K B. Hamins A and Stroup D, Sprinkler, Smoke \& Heat Vent, Draft Curtain Interaction - Large Scale Experiments and Model Development. NISTIR 6196-1, National Institute of Standards and Technology, Gaithersburg, 1998.

[16] Heskestad G. Sprinkler/Hot Layer Interaction. In: NISTGCR-91-590, National Institute of Standards and Technology, Gaithersburg, 1991.

[17] Cooper L Y. The Interaction of an Isolated Sprinkler Spray and a Two-Layer Compartment Fire Environment. Phenomena and Model Simulations. Fire Safety Journal, 1995; 25: 89-107.

[18] Cooper L Y. The Interaction of an Isolated Sprinkler Spray and a Two-Layer Compartment Fire Environment. International Journal Heat and Mass Transfer, 1995; 38: 679-690.

[19] Sheppard D T. Spray Characteristics of Fire Sprinklers. PhD dissertation, Northwestern University, Evanston, 2002

[20] NFPA13HB. Automatic Sprinkler System Handbook. 2002 Edition. USA, National Fire Protection Association, 2002.

[21] Chow W K, Shek L C. Physical Properties of a Sprinkler Water Spray. Fire and Material, 1993; 17: 279-292.

[22] Yu H Z. Investigation of Spray Patterns of Selected Sprinklers with the FMRC Drop Size Measuring System. Fire Safety Science - Proceedings of the First International Symposium, International Association for Fire Safety Science, 1986, pp. 1165-1176.

[23] Chan T S. Measurement of Water Density and Droplet Size Distributions of Selected ESFR Sprinklers. Journal of Fire Protection Engineering, 1994; 6: 79-87.

[24] Hu L H, Huo R, Yang R X, He W H, Wang H B and Li Y Z. Full scale experiments on studying smoke spread in a road tunnel, Fire Safety Science-Proceedings of The Eighth International Symposium, Sep., 2005, Beijing, China, P. 1437-1448.

[25] Hu L H, Huo R, Chow W K, Wang H B, Yang R X. Decay of buoyant smoke layer temperature along the longitudinal direction in tunnel fires, Journal of Applied Fire Science, Vol. 13 (1), P. 49-73, 2004-2005 
[26] Yi L. Study on Smoke Movement and Management in Atrium Building, Ph.D thesis, University of Science and Technology of China, Hefei, 2005. 


\section{Figure Captions}

Figure 1: Schematic view of interaction of smoke layer with sprinkler spray

Figure 2: Pulling down of smoke layer column element by sprinkler spray

Figure 3: Experimental rig and the sprinkler

Figure 4: Typical photos of stable smoke layer for tests A1 and C2

Figure 5: Photos of "smoke logging” plume for test series of C3-C8 with increasing sprinkler spray pressure

Figure 6: Experimental and calculated values of $L$ varying with the increase of $p_{d}$

Figure 7: Variation of moving distance of the smoke layer column element and smoke layer temperature rise with sprinkler operating pressure 
Table 1: Summary of the tests

\begin{tabular}{|c|c|c|c|c|c|c|c|c|c|c|}
\hline \multirow{2}{*}{$\begin{array}{l}\text { Pool } \\
\text { fire } \\
\text { type }\end{array}$} & \multirow{2}{*}{$\begin{array}{l}\text { Pool } \\
\text { size } \\
\left(m^{2}\right)\end{array}$} & \multirow{2}{*}{$\begin{array}{l}\text { Test } \\
\text { No. }\end{array}$} & \multirow{2}{*}{$\begin{array}{l}\text { HRR } \\
(k W)\end{array}$} & \multirow{2}{*}{$\begin{array}{l}\text { Sprinkler } \\
\text { operating } \\
\text { pressure } \\
(\mathrm{MPa})\end{array}$} & \multirow{2}{*}{$\begin{array}{l}\text { Ambient } \\
\text { temperature } \\
\text { (K) }\end{array}$} & \multirow{2}{*}{$\begin{array}{l}\text { Average } \\
\text { temperature } \\
\text { rise of the } \\
\text { smoke layer } \\
\text { (K) }\end{array}$} & \multicolumn{2}{|c|}{$\begin{array}{l}\text { Length of the "smoke } \\
\text { logging” plume } \\
(m)\end{array}$} & \multirow[t]{2}{*}{$D_{0}$} & \multirow[t]{2}{*}{$B_{0}$} \\
\hline & & & & & & & Measured & Calculated & & \\
\hline \multirow{5}{*}{ A } & \multirow{5}{*}{0.25} & A1 & 200 & 0.03 & 296 & 13.1 & 2.1 & 2.0 & 0.79 & 1.07 \\
\hline & & A2 & 200 & 0.04 & 300 & 8.8 & 2.4 & 2.07 & 1.16 & 0.72 \\
\hline & & A3 & 200 & 0.05 & 296 & 6.5 & 2.7 & 2.43 & 1.57 & 0.54 \\
\hline & & A4 & 200 & 0.06 & 300 & 5.8 & 3.1 & 2.99 & 2.00 & 0.48 \\
\hline & & A5 & 200 & 0.07 & 296 & 5.3 & 3.8 & 3.61 & 2.45 & 0.45 \\
\hline \multirow{6}{*}{ B } & \multirow{6}{*}{0.36} & B1 & 248 & 0.03 & 296 & 12.6 & 2.0 & 2.0 & 0.79 & 1.03 \\
\hline & & B2 & 248 & 0.04 & 300 & 9.0 & 2.3 & 2.05 & 1.16 & 0.73 \\
\hline & & B3 & 248 & 0.05 & 296 & 7.2 & 2.5 & 2.32 & 1.57 & 0.60 \\
\hline & & B4 & 248 & 0.06 & 300 & 6.5 & 2.9 & 2.76 & 2.00 & 0.54 \\
\hline & & B5 & 248 & 0.07 & 296 & 6.3 & 3.5 & 3.15 & 2.45 & 0.53 \\
\hline & & B6 & 248 & 0.09 & 296 & 5.9 & 4.0 & 4.11 & 3.43 & 0.49 \\
\hline \multirow{8}{*}{$\mathrm{C}$} & \multirow{8}{*}{0.64} & C1 & 476 & 0.03 & 298 & 31.0 & 2.1 & 2.0 & 0.79 & 2.38 \\
\hline & & C2 & 476 & 0.05 & 298 & 23.8 & 2.1 & 2.0 & 1.57 & 1.87 \\
\hline & & C3 & 476 & 0.07 & 298 & 15.0 & 2.3 & 2.12 & 2.45 & 1.21 \\
\hline & & $\mathrm{C} 4$ & 476 & 0.08 & 298 & 13.9 & 2.5 & 2.26 & 2.93 & 1.12 \\
\hline & & C5 & 476 & 0.09 & 298 & 13.0 & 2.8 & 2.45 & 3.43 & 1.05 \\
\hline & & C6 & 476 & 0.1 & 298 & 11.3 & 3.1 & 2.8 & 3.96 & 0.92 \\
\hline & & C7 & 476 & 0.115 & 298 & 10.5 & 3.5 & 3.25 & 4.75 & 0.86 \\
\hline & & C8 & 476 & 0.13 & 298 & 10.5 & 3.9 & 3.56 & 5.59 & 0.86 \\
\hline
\end{tabular}




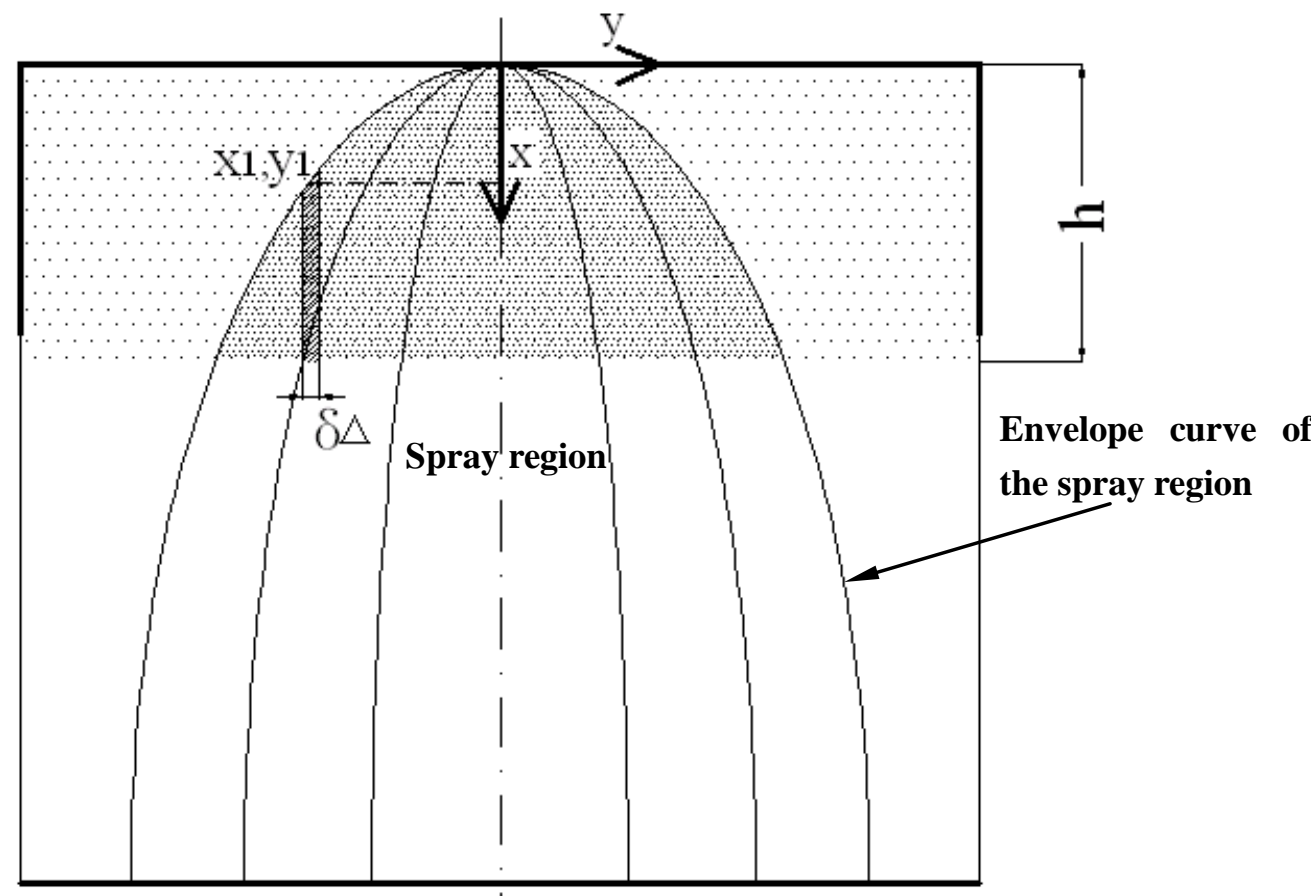

Figure 1: Schematic view of interaction of smoke layer with sprinkler spray 


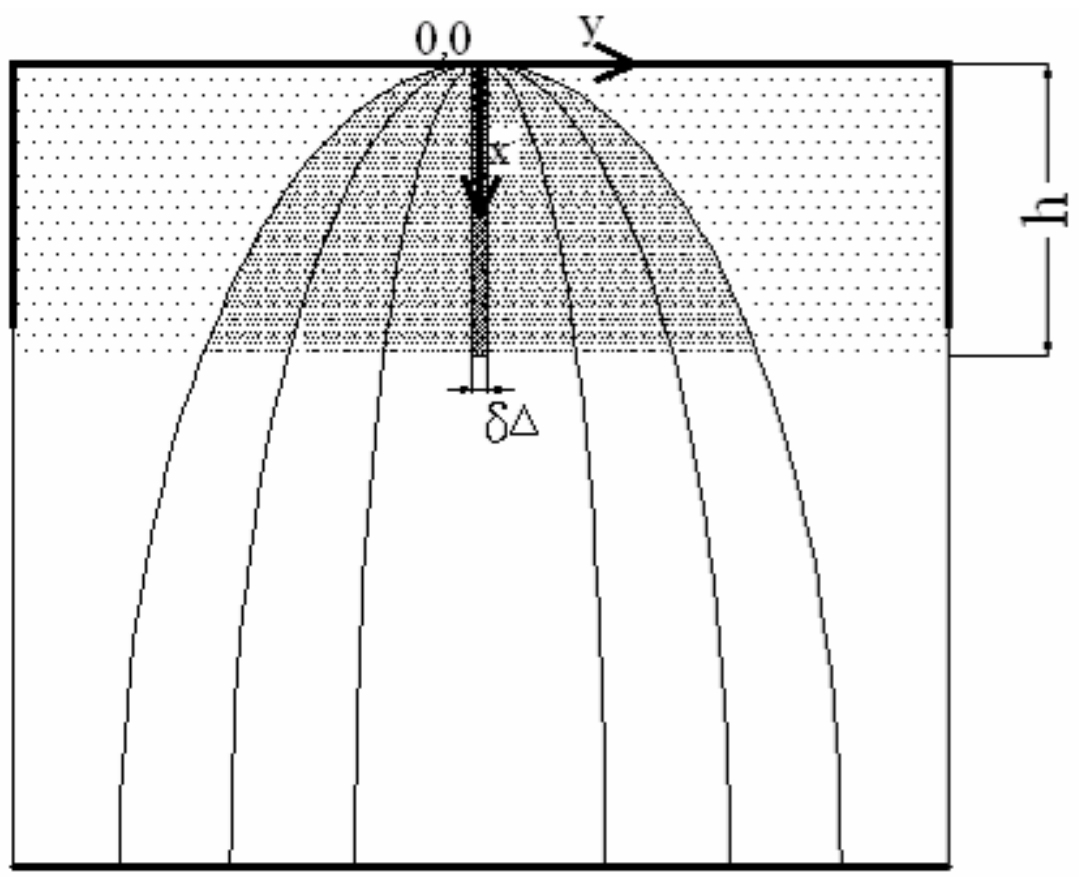

(a) Initial condition with drag force $D_{0}$

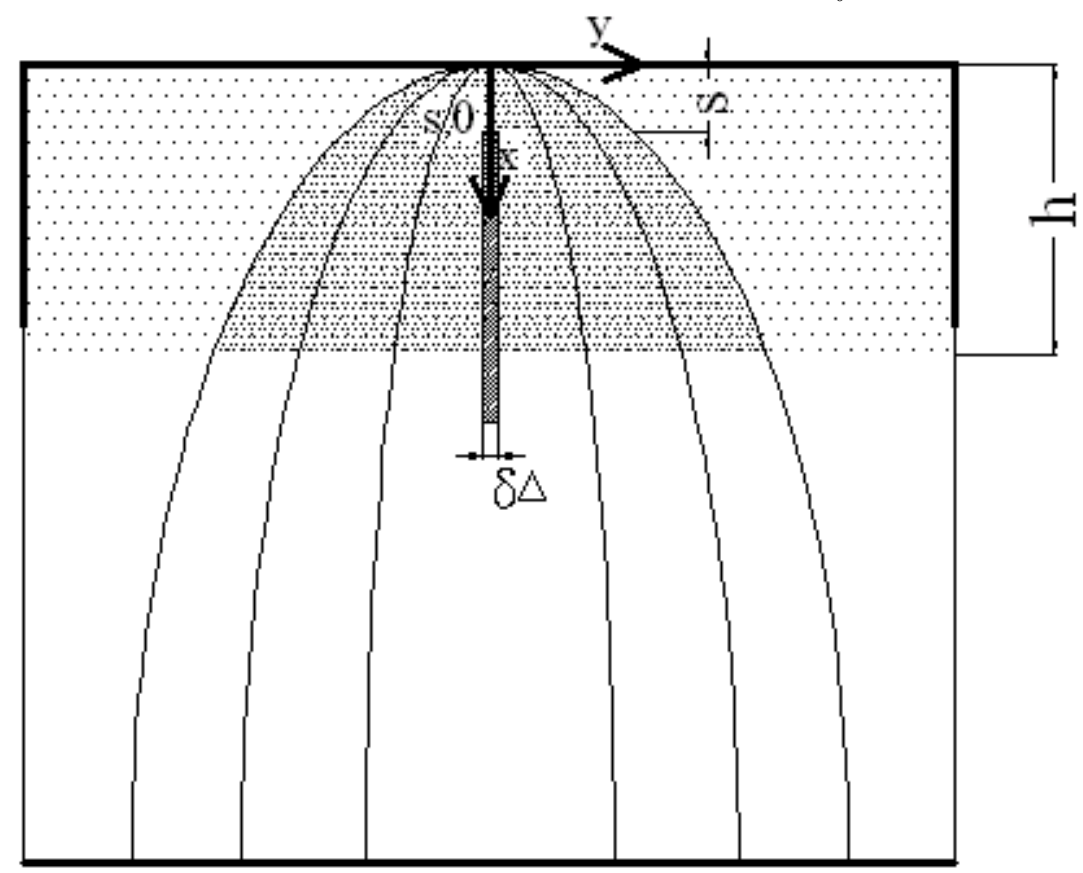

(b) The smoke layer column element move down with a distance of $S$

Figure 2: Pulling down of smoke layer column element by sprinkler spray 


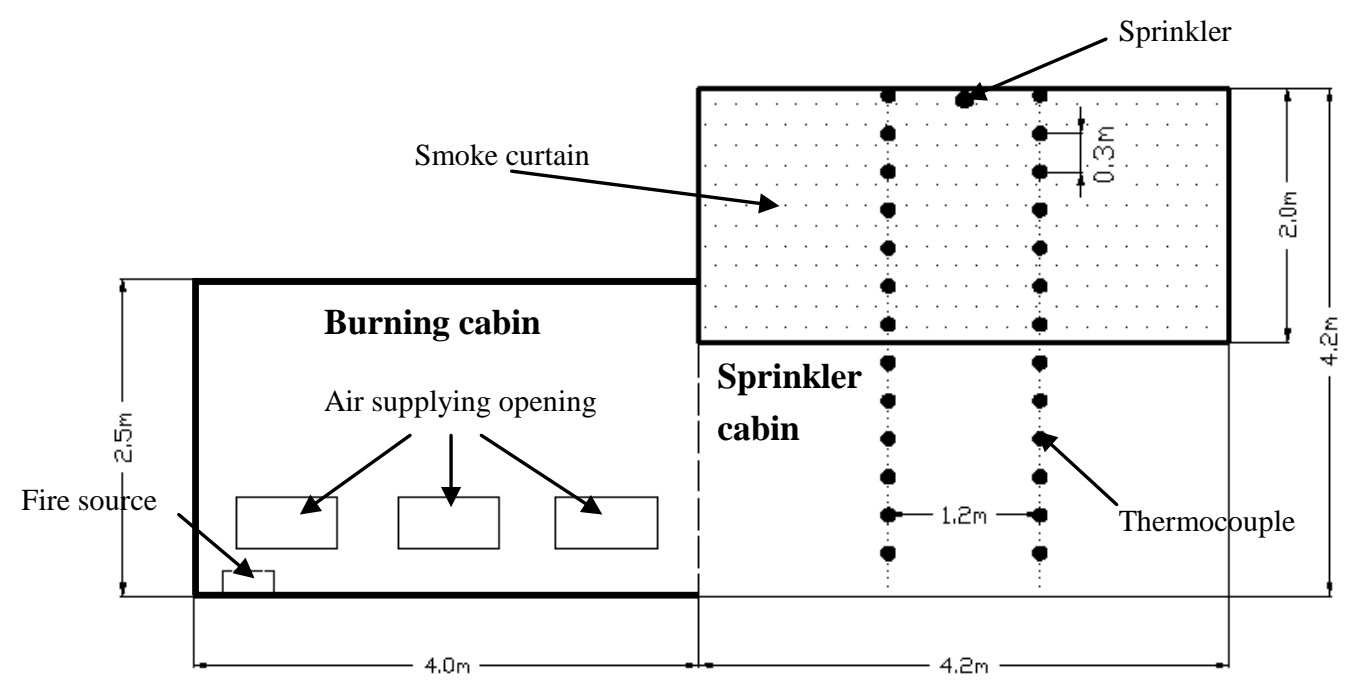

(a) Schematic view of the experimental rig

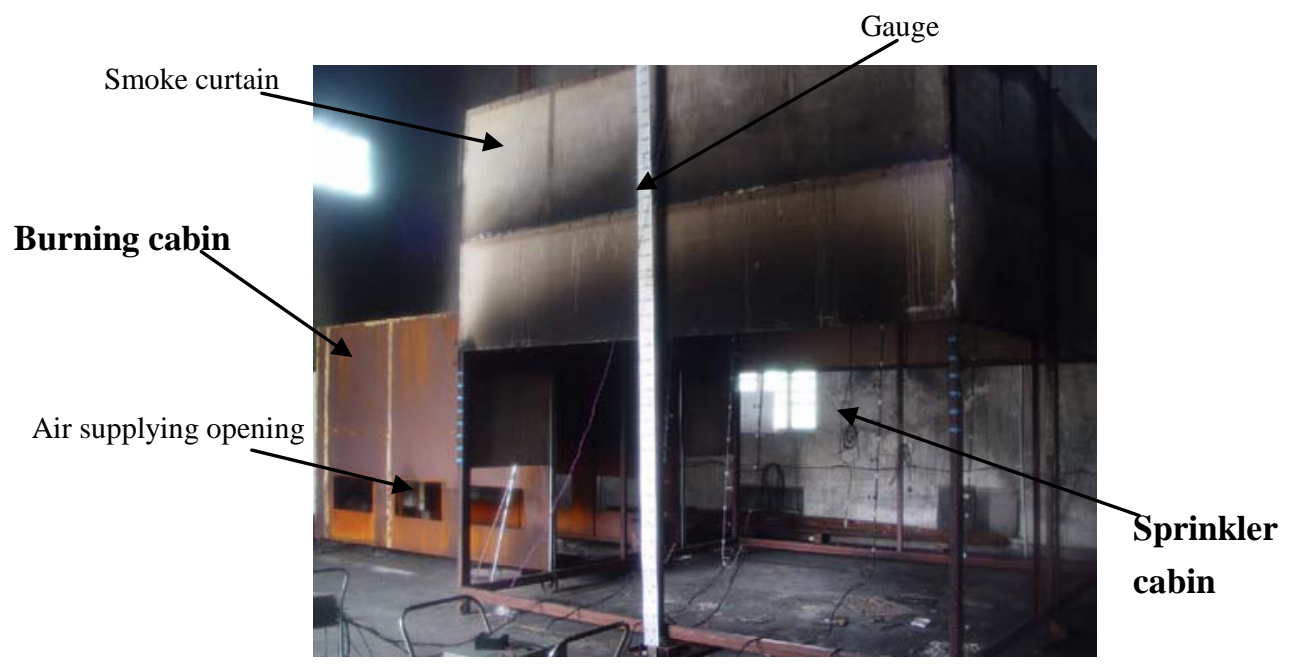

(b) Photo of the experimental rig

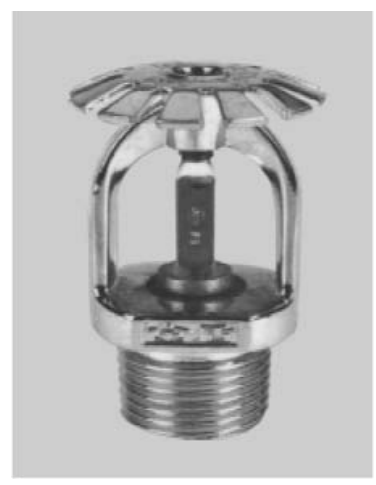

(c) Photo of the sprinkler

Figure 3: Experimental rig and the sprinkler 


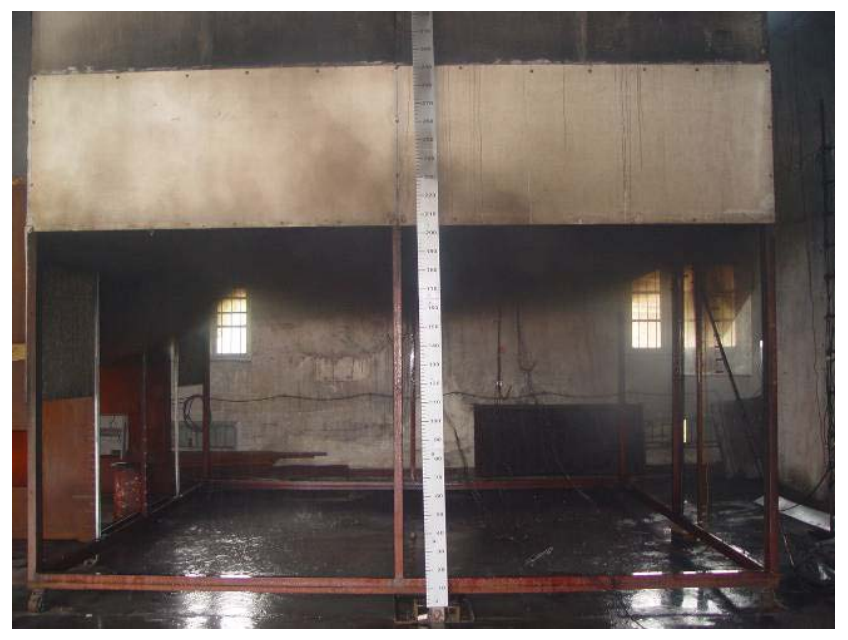

(a) A1

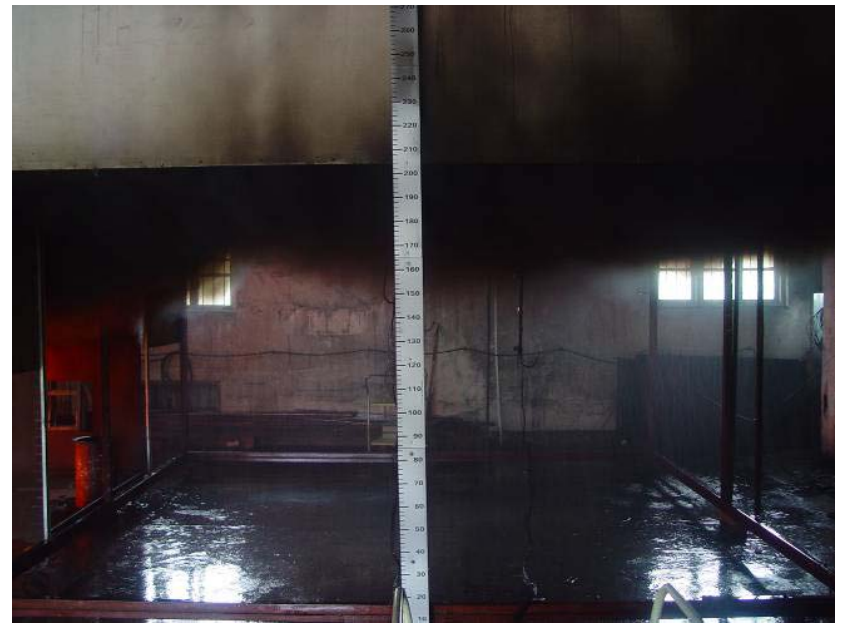

(b) C2

Figure 4: Typical photos of stable smoke layer for tests A1 and C2 


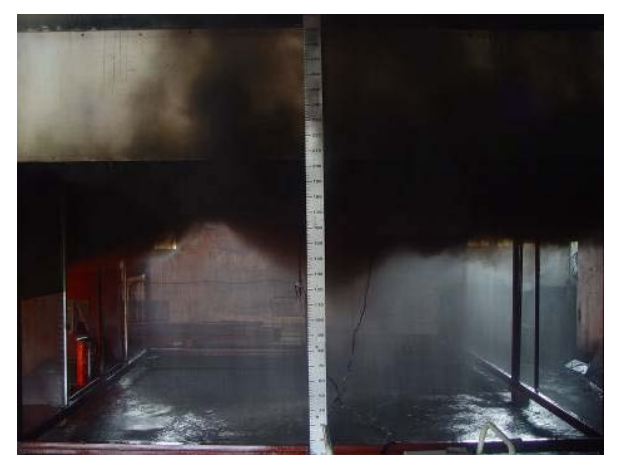

(a) C3

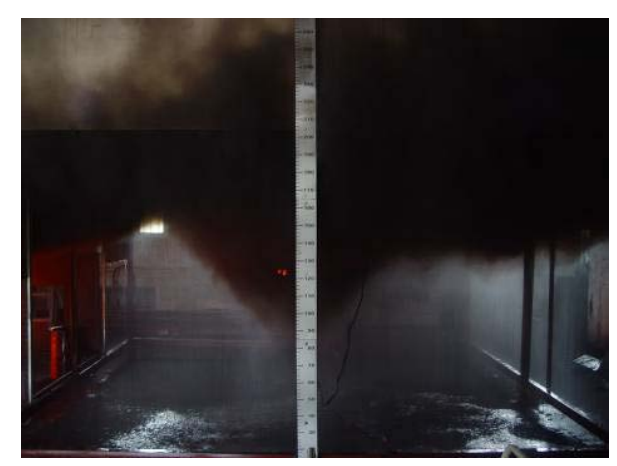

(c) $\mathrm{C5}$

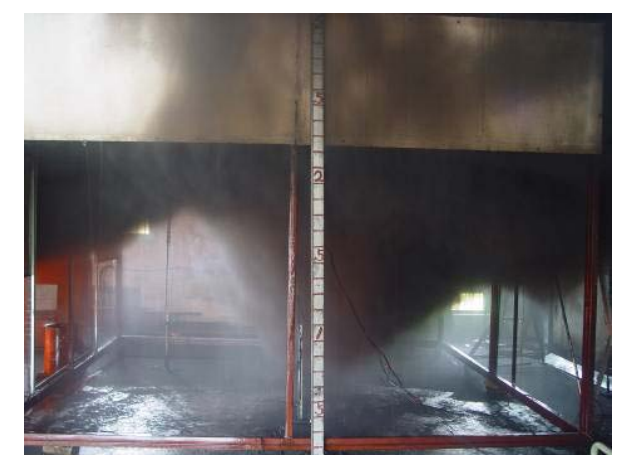

(e) C7

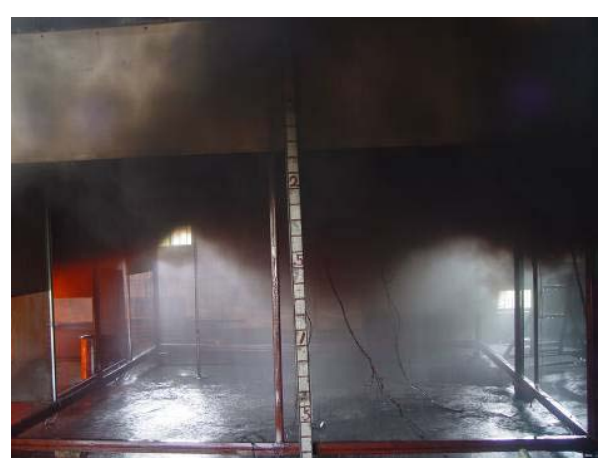

(b) $\mathrm{C} 4$

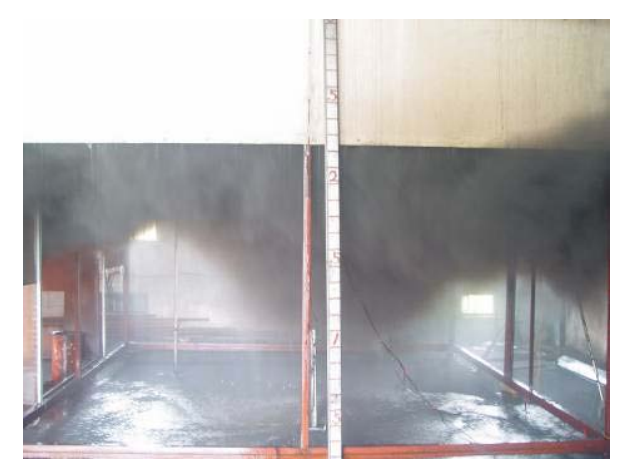

(d) C6

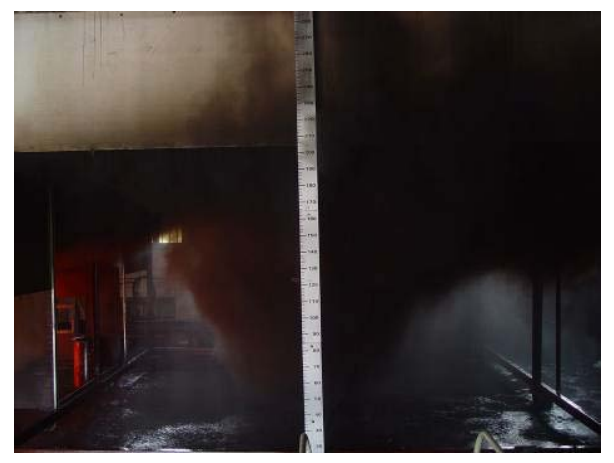

(f) $\mathrm{C} 8$

Figure 5: Photos of "smoke logging" plume for test series of C3-C8 with increasing sprinkler spray pressure 


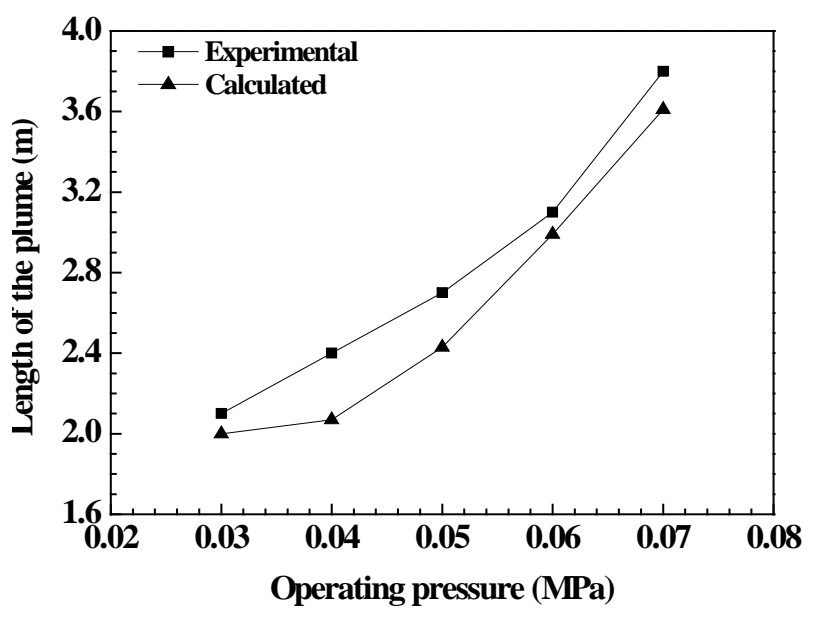

(a) Pool fire $\mathrm{A}$

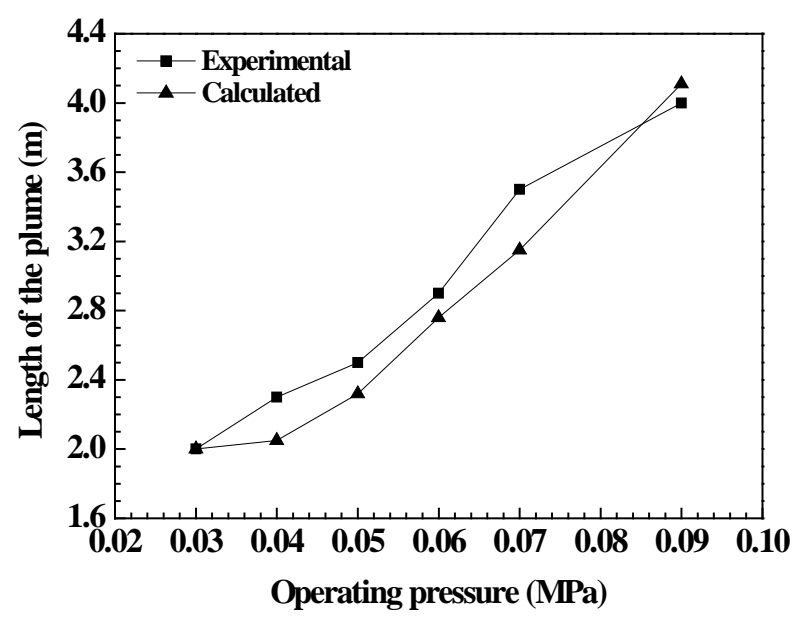

(b) Pool fire B

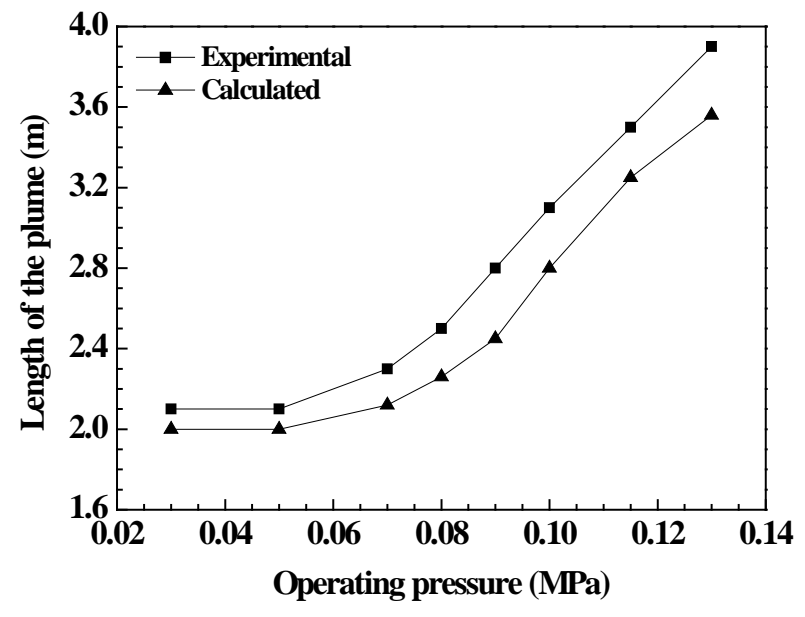

(c) Pool fire C

Figure 6: Experimental and calculated values of $L$ with the increase of $p_{d}$ 


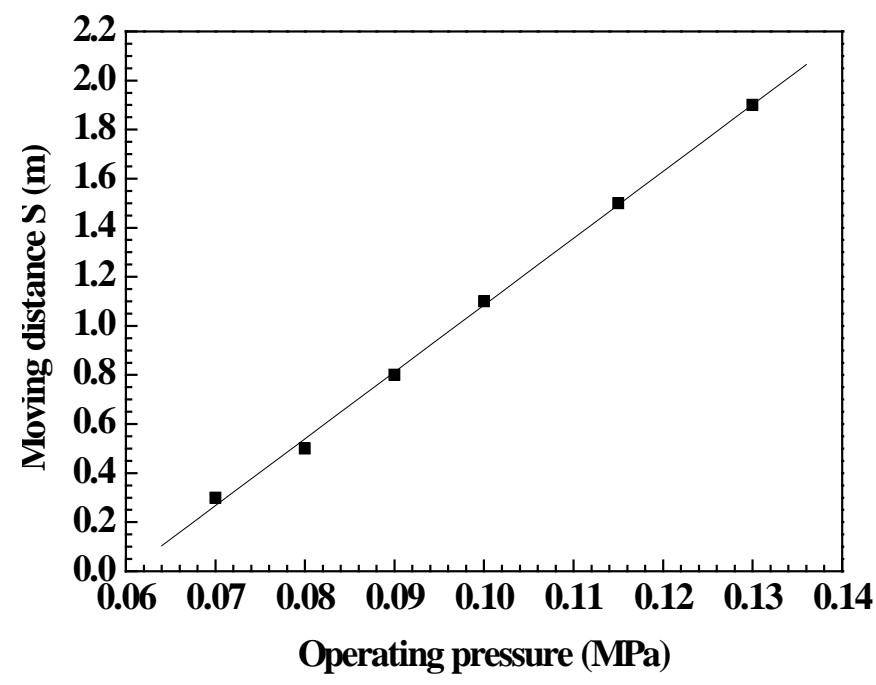

(a) Moving distance of the element

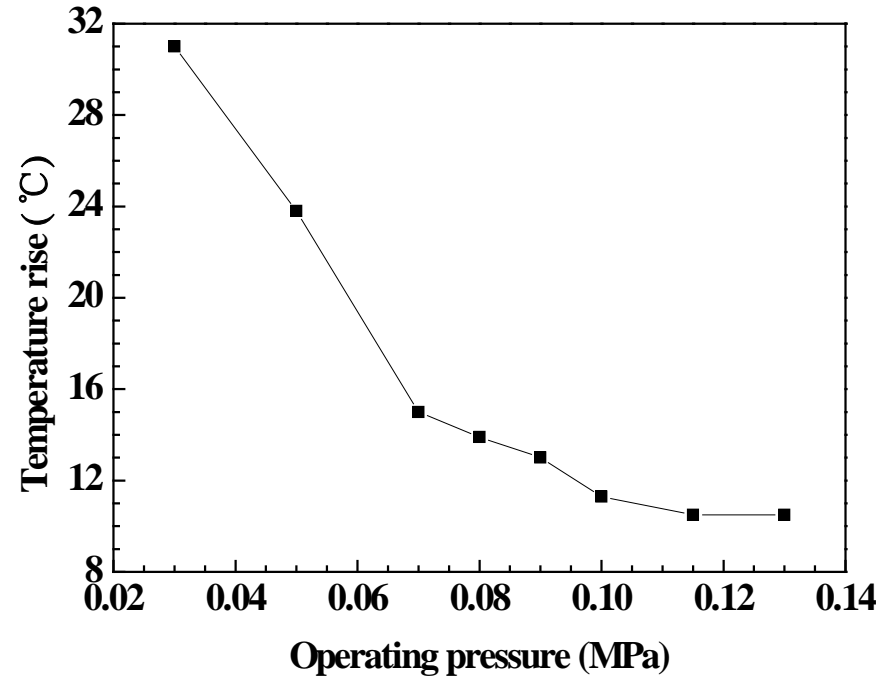

(b) Temperature rise of the smoke layer

Figure 7: Variation of moving distance of the smoke layer column element and smoke layer temperature rise with sprinkler operating pressure 